\title{
Ozone Differentially Affects Perception of Plant Volatiles in Western Honey Bees
}

\author{
Stefan Dötterl ${ }^{1}$ (D) $\cdot$ Marina Vater $^{2} \cdot$ Thomas Rupp $^{1} \cdot$ Andreas Held $^{3}$
}

Received: 8 April 2016 /Revised: 4 June 2016 / Accepted: 7 June 2016 /Published online: 25 June 2016

(C) The Author(s) 2016. This article is published with open access at Springerlink.com

\begin{abstract}
Floral scents play a key role in mediating plantpollinator interactions. Volatile organic compounds (VOCs) emitted by flowers are used by flower visitors as olfactory cues to locate flowers, both from a distance and at close range. More recently it has been demonstrated that reactive molecules such as ozone can modify or degrade VOCs, and this may impair the communication between plants and their pollinators. However, it is not known whether such reactive molecules also may affect the olfactory system of pollinators, and thus not only influence signal transmission but perception of the signal. In this study, we used electroantennographic measurements to determine the effect of increased levels of ozone on antennal responses in western honey bees (Apis mellifera L.). Linalool and 2-phenylethanol, both known to be involved in location of flowers by the bees, and (Z)-3-hexenyl acetate, a widespread green leaf volatile also detected by bees, were used. The results showed that ozone affected antennal responses to the different substances differently. Ozone decreased antennal responses to (Z)-3-hexenyl acetate, whereas responses to linalool and 2-phenylethanol were not influenced by ozone. Overall, the study does not provide evidence that pollination by honey bees is impaired by damage in the olfactory system of the bees caused by increased levels of ozone, at least when linalool and 2-phenylethanol are the attractive
\end{abstract}

Stefan Dötterl

Stefan.doetterl@sbg.ac.at

1 Department of Ecology \& Evolution, Plant Ecology, University of Salzburg, 5020 Salzburg, Austria

2 Department of Plant Systematics, University of Bayreuth, 95440 Bayreuth, Germany

3 Bayreuth Center of Ecology and Environmental Research, University of Bayreuth, 95440 Bayreuth, Germany signals. However, the results also suggest that ozone can change the overall perception of an odor blend. This might have negative effects in pollination systems and other organismic interactions mediated by specific ratios of compounds.

Keywords Apis mellifera $\cdot$ Electroantennography $\cdot$ Floral and vegetative volatiles $\cdot$ Atmospheric pollutant

\section{Introduction}

Pollination by insects is a key ecosystem service not only in natural but also in managed terrestrial ecosystems (Klein et al. 2007). The economic value of insect pollination is suggested to be worldwide $€ 153$ billion per year (Gallai et al. 2009). Floral scents play a crucial role in mediating plant-insect interactions and are used by pollinators to locate flowers (e.g., Dötterl and Vereecken 2010). Pollinators utilize a wide range of scent components both as long distance signals and to discriminate among rewarding and non-rewarding flowers at close range (e.g., Dötterl and Vereecken 2010). Recent studies indicate that chemical communication between plants and their pollinators can be disrupted by pollutants, such as nitrogen oxides (e.g., derived from diesel exhaust) and ozone (Farré-Armengol et al. 2016; Girling et al. 2013; Lusebrink et al. 2015). This is because the oxidative airborne pollutants structurally affect or rapidly degrade floral volatiles (FarréArmengol et al. 2016; Girling et al. 2013; McFrederick et al. 2009). As a result, the distance over which floral scents can be detected by pollinators is decreased (Farré-Armengol et al. 2016) with the effect that plants might be negatively affected in recruiting insect pollinators, and insects in finding food sources.

Despite the knowledge on the effects of atmospheric pollutants on volatile signals, it is not known whether these 
compounds can directly affect the olfactory system in insects (McFrederick et al. 2009). The aim of this study was to fill this gap in our knowledge by investigating the effect of ozone fumigation on antennal sensitivity in western honey bees (Apis mellifera L.). We used ozone because of its importance as an air pollutant. Furthermore, ozone levels in the troposphere have increased when compared to pre-industrial times, and are assumed to continue to increase (FarréArmengol et al. 2016, and references therein). The western honey bee was selected as our insect system because it is an important model system for sensory physiology and behavior (Dötterl and Vereecken 2010, and references therein), and the most important pollinator of crops (Klein et al. 2007). Specifically, we asked whether antennal responses to the widespread floral volatiles linalool and 2-phenylethanol, both known to be attractive to honey bees (Dötterl and Vereecken 2010), are influenced by fumigation of antennae with ozone. We additionally tested the common green leaf volatile (Z)-3-hexenyl acetate, which elicits defensive behaviors (e.g., stinging) in the bees (Henning et al. 1992).

\section{Methods and Materials}

Study System The experiments were carried out using workers of the western honey bee Apis mellifera L., collected in the front of bee hives when returning from foraging at the Ecological Botanical Garden, University of Bayreuth.

\section{Ozone Production and Measurement of Ozone} Concentration Ozone $\left(\mathrm{O}_{3}\right)$ was produced using photolysis of molecular oxygen subjected to UV radiation at a wavelength of $184.9 \mathrm{~nm}$. A mercury Pen-Ray lamp (LSP035, LOT, Leatherhead, UK) provided the required radiation. Ozone concentration of the air passing over the antennae (see below) was continuously measured using a UV photometric Ozone Analyzer (Thermo Scientific (2007), Model 49i Ozone Analyzer, Franklin, MA, USA). Ozone fumigation was performed at a concentration of $1000 \mathrm{ppb}$. Ozone peak concentrations up to $680 \mathrm{ppb}$ were measured between the $1950 \mathrm{~s}$ and 1970s in Los Angeles, CA, USA (Bachmann 2007), while today levels are typically less than $100 \mathrm{ppb}$.

Electroantennography The monoterpene linalool (97\%, Sigma-Aldrich) and aliphatic (Z)-3-hexenyl acetate ( $\geq 98 \%$, Sigma-Aldrich) were used 10 fold diluted $(v / v)$, aromatic 2phenylethanol ( $\geq 99 \%$, Sigma-Aldrich) was used 100-fold diluted $(v / v)$. Paraffin (Uvasol ${ }^{\circledR}$, Merck/VWR) was the diluting agent. The concentrations used elicited antennal responses close to the maxima as determined by dose-response measurements (data not shown).
To investigate the effects of ozone on the perception of the three different volatiles by the bees, electrophysiological experiments were carried out by using a standard electroantennographic (EAG) approach. For measurements, the bee antenna (one per individual) was cut at the base and tip, and mounted between glass micropipette electrodes filled with insect ringer $(8.0 \mathrm{~g} / 1 \mathrm{NaCl}, 0.4 \mathrm{~g} / \mathrm{l}$ $\mathrm{KCl}, 0.4 \mathrm{~g} / \mathrm{l} \mathrm{CaCl}_{2}$ ). The electrodes were connected to silver wires. Antennae were stimulated at 2 min intervals. $20 \mu \mathrm{l}$ of each stimulus were applied on filter paper (Whatman No. 1, $0.4 \times 4.0 \mathrm{~cm}$ ) and then put into a pasteur pipette (15 cm in length). Stimuli were released into a continuous flow of humidified air passing over the antenna with a pulse duration of $0.5 \mathrm{~s}$, and a flow of $10 \mathrm{ml} / \mathrm{s}$ regulated by a CS-01 Stimulus Controller (Syntech, Hilversum, Netherlands). Data were recorded by a twochannel universal serial bus acquisition controller (IDAC2) and analyzed using the software EAGPro 1.0, both provided by Syntech.

Experimental Design Each antenna was exposed to three stimulus sequences, whereas the three sequences consisted either of a single compound and paraffin negative controls (e.g., paraffin - 2-phenylethanol - paraffin) or of the three compounds and paraffin controls (e.g., paraffin - linalool - 2phenylethanol - (Z)-3-hexenyl acetate - paraffin). When using all three compounds in a sequence, they were used in randomized order. Paraffin controls were used for the first and last measurements in a sequence. In control antennae, humidified air passed over the antennae (see above) during all three sequences. In treatment antennae, humidified air enriched with ozone was used for the second sequence (antennae were fumigated for 2 min before and during this sequence), whereas sequences 1 and 3 were as in control antennae. Sample sizes (\# of antennae used $)$ were as follows: linalool $\left(N_{\text {treatment }}=8\right.$, $\left.N_{\text {control }}=10\right), 2$-phenylethanol $\left(N_{\text {treatment }}=18, N_{\text {control }}=19\right)$, (Z)-3-hexenyl acetate $\left(N_{\text {treatment }}=18, N_{\text {control }}=24\right)$.

To ensure that the air which continuously passed over the antenna differed only in ozone concentration, the tubing containing the humidified air was split into two arms before unifying them again. Air in one of these arms was radiated by the UV light (see before). The "ozone-free" arm was protected with aluminium foil, which covered the delivery set-up. By switching the light on or off, air enriched or not enriched with ozone was obtained. The flow in the "ozone arm" was regulated with a clamp to adjust the ozone concentration.

Statistical Analyses To control for differences in antennal sensitivity among antennae, responses to compounds in the first sequence of each antenna were set to $100 \%$. Responses to the same compounds in the following 
sequences are given in percent responses obtained in the first sequence.

Responses in the second and third sequence were analysed by repeated measures ANOVA (STATISTICA 7) to test for differences in antennal response between treatment and control antennae. We also considered the sequence effect, and the interaction effect between treatment and sequence. If appropriate, $t$-tests for independent samples were used for post-hoc comparisons of responses in treatment and control antennae within a specific sequence. $T$-tests for dependent samples were used for post-hoc comparisons to test for a sequence effect within treatment and within control antennae. Data from measurements with one and three stimuli in a sequence were combined for the analyses.

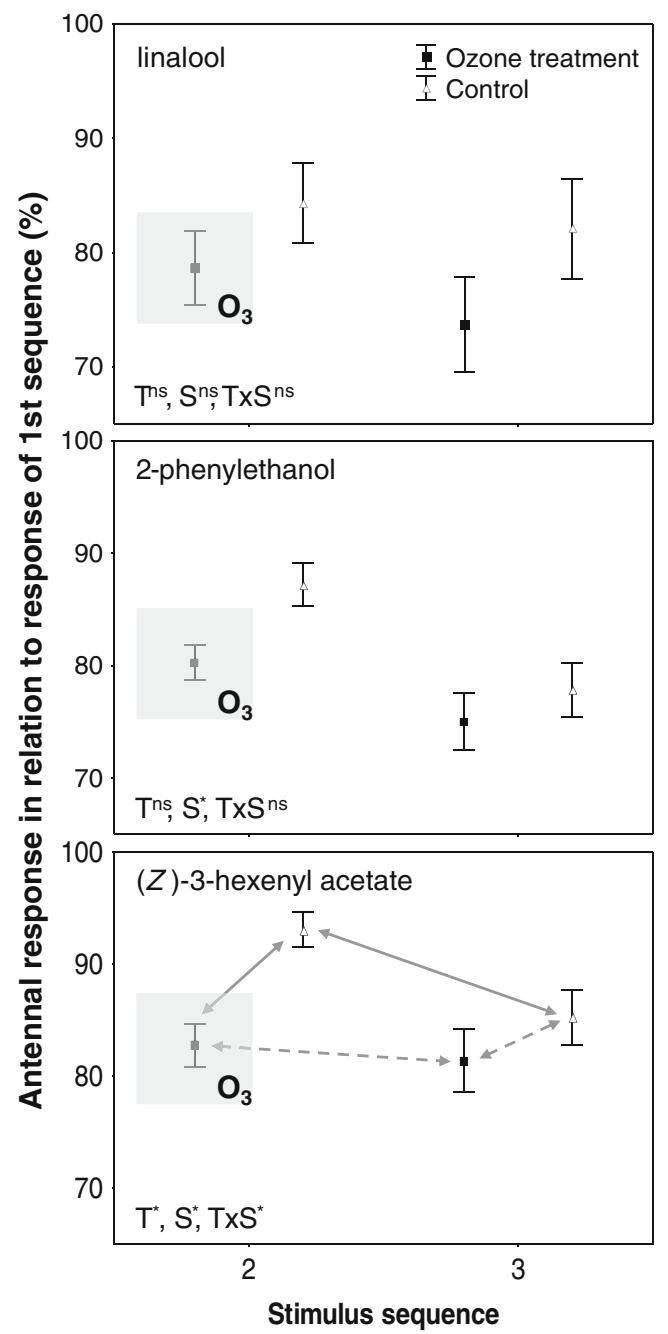

Fig. 1 Electroantennographic (EAG) responses (Mean \pm SE) of honey bees to the three tested substances, with or without ozone fumigation during the 2 nd sequence. None of the antennae were fumigated with ozone during the 3 rd sequence. T: statistical treatment effect, $\mathrm{S}$ : statistical sequence effect, TxS: statistical interaction effect of T and S; outcomes of a repeated measures ANOVA are given as ns: nonsignificant $(P>0.05)$ or $*$ : significant at $P<0.05$. Solid and dashed grey lines show significant $(P<0.001)$ and non-significant $(P>0.05)$ effects, respectively, as indicated by post-hoc tests

\section{Results and Discussion}

The electroantennographic experiments revealed that ozone affected antennal responses to different substances differently (Fig. 1). For linalool, no effect of ozone fumigation was detected $\left(F_{1,16}=2.02, P>0.05\right)$, and outcomes were non-significant for the sequence $\left(F_{1,16}=2.78, P>0.05\right)$ and interaction $\left(F_{1,16}=0.90, P>0.05\right)$ effects. Responses to 2-phenylethanol were smaller in the $3 \mathrm{rd}$ than the 2 nd sequence $\left(F_{1,35}=31.83\right.$, $P<0.001)$, independent of whether antennae were fumigated with ozone or not (treatment: $F_{1,35}=3.04, P>0.05$, interaction effect: $\left.F_{1,35}=2.46, P>0.05\right)$. Responses to $(Z)$-3-hexenyl acetate were affected by ozone fumigation $\left(F_{1,40}=5.66\right.$, $P=0.022)$, and for this compound we also obtained significant sequence $\left(\mathrm{F}_{1,40}=18.52, P<0.001\right)$ and interaction $\left(F_{1,40}=9.09, P=0.005\right)$ effects. Post-hoc analyses revealed that antennal responses were reduced only during ozone fumigation, i.e., in the 2 nd sequence, whereas responses between control and treatment antennae did not differ in the 3rd sequence. A sequence effect was found only for control antennae, but not for antennae treated with ozone (Fig. 1).

This study shows that ozone fumigation results in a decrease in antennal responses to $(Z)$-3-hexenyl acetate, whereas responses to linalool and 2-phenylethanol were not significantly influenced by ozone, despite a general trend of smaller responses in antennae treated with ozone (Fig. 1). Thus, it seems that traits/ structures involved in the detection of different compounds are differently affected by ozone. We only can speculate that ozone oxidizes odorant-binding proteins or olfactory receptors (see also McFrederick et al. 2009), both key proteins in olfaction (Leal 2013), to various extents. Empirical evidence for oxidation by ozone of such proteins is missing thus far, however, studies on other organisms and other tissues have shown that ozone can alter protein structures (e.g., Tognini et al. 1997), making oxidation by ozone of proteins involved in olfaction also likely.

In our experiments, compounds were released into the humidified air, which was or was not enriched with ozone. Thus, ozone also may have oxidized/degraded the volatiles themselves, especially linalool and ( $Z$ )-3-hexenyl acetate (Atkinson et al. 1995). However, compounds reached the antennae less than a second after having them released in the ozonated air. At 1000 ppb ozone, a fraction of only $1.1 \%$ of the most reactive (towards ozone) compound linalool is degraded within $1 \mathrm{~s}$ (Atkinson et al. 1995). Thus, ozonolysis of the compounds was likely not relevant in our study.

We used ozone concentrations rarely reached in nature, and future studies need to show whether detection of volatiles also is influenced by smaller ozone concentrations. Ozone did not affect antennal responses to the two floral volatiles linalool and 2-phenylethanol, despite these high concentrations used. Thus, pollination systems mediated by these compounds would seem not to be impaired by increased levels of ozone causing oxidations in the antennae of honey bees. However, as 
we found an effect on perception of the aliphatic green-leaf volatile (Z)-3-hexenyl acetate, it seems worthwhile to tests for an effect of ozone on perception of other floral volatiles using various concentrations of ozone and various exposure times. Exposure of bees/antennae to continuously increased levels may induce damage not considered in this work (e.g., oxidation of non-antennal proteins). Further, the differential effect of ozone on the sensing of compounds will change the overall perception of an odor blend. This could add another problem to bees and possibly also to other pollinators, especially if relative proportions in a blend play an important role in the processing of the information.

Before our study it was known that volatile-mediated interactions are prone to disruption by air pollutants through direct effects of phytotoxic pollutants on VOC emissions and degradation of VOCs by reactive pollutants in the air (FarréArmengol et al. 2016, and references therein). We show that direct effects of oxidizing pollutants on the receiving organisms also need to be considered. Relatively minor effects by ozone on pollinators observed in this study might be greater if coupled with a change in volatile emissions through phytotoxicity and a loss of VOCs through degradation.

\footnotetext{
Acknowledgments Open access funding provided by Paris Lodron University of Salzburg. We thank Andreas Jürgens and two anonymous reviewers for helpful comments on earlier versions of the manuscript.
}

Open Access This article is distributed under the terms of the Creative Commons Attribution 4.0 International License (http:// creativecommons.org/licenses/by/4.0/), which permits unrestricted use, distribution, and reproduction in any medium, provided you give appropriate credit to the original author(s) and the source, provide a link to the Creative Commons license, and indicate if changes were made.

\section{References}

Atkinson R, Arey J, Aschmann SM, Corchnoy SB, Shu Y (1995) Rate constants for the gas-phase reactions of cis-3-hexen-1-ol, cis-3hexenylacetate, trans-2-hexenal, and linalool with $\mathrm{OH}$ and $\mathrm{NO}_{3}$ radicals and $\mathrm{O}_{3}$ at $296 \pm 2 \mathrm{~K}$, and $\mathrm{OH}$ radical formation yields from the $\mathrm{O}_{3}$ reactions. In $\mathrm{J}$ Chem Kinet 27:941-955

Bachmann J (2007) Will the circle be unbroken: a history of the U.S. national ambient air quality standards. J Air Waste Manage Assoc 57:652-697

Dötterl S, Vereecken NJ (2010) The chemical ecology and evolution of bee-flower interactions: a review and perspectives. Can J Zool 88: 668-697

Farré-Armengol G, Peñuelas J, Li T, Yli-Pirilä P, Filella I, Llusia J, Blande JD (2016) Ozone degrades floral scent and reduces pollinator attraction to flowers. New Phytol 209:152-160

Gallai N, Salles JM, Settele J, Vaissière BE (2009) Economic valuation of the vulnerability of world agriculture with pollinator decline. Ecol Econ 68:810-821

Girling RD, Lusebrink I, Farthing E, Newman TA, Poppy GM (2013) Diesel exhaust rapidly degrades floral odours used by honeybees. Sci Report 3:2779

Henning JA, Peng YS, Montague MA, Teuber LR (1992) Honey-bee (hymenoptera, Apidae) behavioral-response to primary alfalfa (Rosales, Fabaceae) floral volatiles. J Econ Entomol 85:233-239

Klein AM, Vaissière BE, Cane JH, Steffan-Dewenter I, Cunningham SA, Kremen C, Tscharntke T (2007) Importance of pollinators in changing landscapes for world crops. Proc R Soc B 274:303-313

Leal WS (2013) Odorant reception in insects: roles of receptors, binding proteins, and degrading enzymes. Annu Rev Entomol 58:373-391

Lusebrink I, Girling RD, Farthing E, Newman TA, Jackson CW, Poppy GM (2015) The effects of diesel exhaust pollution on floral volatiles and the consequences for honey bee olfaction. J Chem Ecol 41:904-912

McFrederick QS, Fuentes JD, Roulston T, Kathilankal JC, Lerdau M (2009) Effects of air pollution on biogenic volatiles and ecological interactions. Oecologia 160:411-420

Tognini M, Ranieri A, Castagna A, Nali C, Lorenzini G, Soldatini GF (1997) Ozone-induced alterations in thylakoid protein patterns in pumpkin leaves of different age. Phyton 37:277-282 